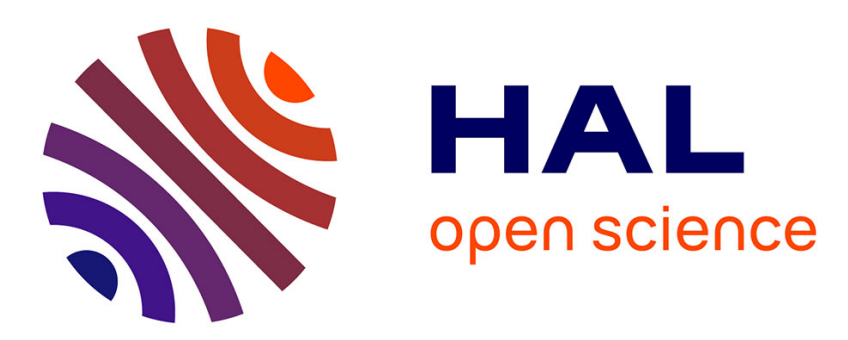

\title{
Influence of plastic strain on magnetic behaviour of non-oriented Fe-3Si and application to manufacturing test by punching
}

\author{
Olivier Hubert, E. Hug
}

\section{- To cite this version:}

Olivier Hubert, E. Hug. Influence of plastic strain on magnetic behaviour of non-oriented Fe-3Si and application to manufacturing test by punching. Materials Science and Technology, 1995, 11 (5), pp.482 - 487. 10.1179/mst.1995.11.5.482 . hal-01003013

\section{HAL Id: hal-01003013 \\ https://hal.science/hal-01003013}

Submitted on 11 Jul 2017

HAL is a multi-disciplinary open access archive for the deposit and dissemination of scientific research documents, whether they are published or not. The documents may come from teaching and research institutions in France or abroad, or from public or private research centers.
L'archive ouverte pluridisciplinaire HAL, est destinée au dépôt et à la diffusion de documents scientifiques de niveau recherche, publiés ou non, émanant des établissements d'enseignement et de recherche français ou étrangers, des laboratoires publics ou privés. 


\section{Influence of plastic strain on magnetic behaviour of non-өriented Fe-3Si and application to manu- facturing test by punching}

O.HUBERT, E.HUG

Division électromécanique. Département de Génie Mécanique. Centre de recherches de Royallieu. Université de Technologie de Compiègne, BP 649, 60206 COMPIEGNE cedex. FRANCE. 


\section{$\underline{\text { Abstract }}$}

The prediction of core losses in a rotating electrical machine requires generally a numerical approach (finite element or integral method). However the magnetic characteristics obtained through standard Epstein facility and inserted in the numerical programs predict losses which are quite different from the experimental ones. This difference can be partly explained by the presence of plastic strain close to the cutting edge of manufactured motor sheets. Firstly, numerical functions are established to predict the change of the magnetization and loss curves with respect to the plastic strain level. Secondly, a microhardness test is used to measure the local plastic strain directly on the manufactured sheet. Finally we obtain relations between the main magnetic properties and the position on the sheet : profiles of magnetic properties which are determined allow an improvement of the numerical approach . 


\section{Introduction}

Core losses due to the magnetic rate of flux density in a soft ferromagnetic material depend on phenomena as complex as hysteresis losses and eddy current losses 1-2. Thus the prediction of core losses in a rotating electrical machine is difficult and requires a numerical approach (i.e. finite element methods ${ }^{3}$ ). But, even if the functions used in the numerical procedures are based on magnetization characteristics obtained through standard Epstein facility, the predicted losses remain smaller than the experimental ones ${ }^{2-3}$.

It has been checked by many authors 4-5-6 that the microscopic shape of a ferromagnetic material has a fundamental role on its magnetic properties . In particular, plastic strains, resulting in the generation of dislocations, cause the magnetic properties of a non oriented (N.O.) 3\% Silicon - Iron sheet to deteriorate ${ }^{3-}$ 7. Plastic deformation could be caused to a rotating electrical machine sheet during its manufacture and could damage its magnetic properties.

The aim of this work is to reveal the presence of this type of manufacturing damage which could explain the differences between calculated and experimental losses. Preliminary work consisted of applying the magnetic properties of a plastically deformed sheet to the whole meshed volume ${ }^{7}$.

In this paper, the approach is now twofold : firstly, the effect of plastic deformation on the magnetic properties of a N.O. 3\% Silicon - Iron sheet ( $0.5 \mathrm{~mm}$ thick) has been modelled from experimental measurements carried out with an A.C. $50 \mathrm{~Hz}$ supply. This involves a tranformation of classical models. Secondly, the local plastic strain has been directly identified in the manufactured sheet close to the cutting edge. The results lead to the determination of the profile of magnetic properties. 


\section{Evolution of magnetic properties with plastic deformation}

\subsection{Experimental procedure}

Classical techniques for the measurement of magnetic properties (standard Epstein facility) are not suitable for an investigation of strained materials ; a new magnetic circuit has consequently been manufactured. As shown in figure 1 this consists of a ferromagnetic yoke where a magnetic flux $\phi(t)$ is created by a field coil. $\phi(t)$ is channelled into a tensile-strained specimen so that the effect of plastic deformation can be measured. This magnetic circuit is used with a $50 \mathrm{~Hz}$ alternating current. Specimens, which consist of $200 \mathrm{~mm}$ long, $20 \mathrm{~mm}$ wide, and $0.5 \mathrm{~mm}$ thick bands, have been chosen in the rolling and transverse directions (results are averaged to avoid any texture effect). They have been annealed $\left(720^{\circ} \mathrm{C}, 2 \mathrm{H}, \mathrm{P}\left(\mathrm{O}_{2}\right)=2.10^{-4}\right.$ Torr $)$ and plastically deformed from $0 \%$ up to $20 \%$ (plastic deformation level $=\varepsilon_{\mathrm{p}}(\%)$ ) at room temperature and constant extension rate. A coil positioned on the deformed sample produces an electromotive force $\mathrm{e}(\mathrm{t})$ due to the rate of magnetic flux ; the $\mathrm{e}(\mathrm{t})$ and the excitation current $\mathrm{i}(\mathrm{t})$ signals are stored and used to produce a hysteresis loop giving the magnetic flux density $\mathrm{B}(\mathrm{t})$ as a function of the magnetic field $\mathrm{H}(\mathrm{t})$.

From Faraday's law, $B(t)$ is proportional to the integrated $e(t)$ function : $V(t)$.

$$
B(t)=\frac{\alpha}{S} \cdot \int e(t) d t=\frac{\alpha \cdot V(t)}{S \cdot n}
$$

with : $\alpha$ : integrating constant

$\mathrm{S}:$ specimen cross section

$\mathrm{n}$ : number of turns of the magnetic flux density coil 
Ampere's law states that $\mathrm{H}(\mathrm{t})$ is proportional to $\mathrm{i}(\mathrm{t})$ :

$$
H(t)=\frac{i(t) \cdot N}{L}
$$

with : L : medium in-yoke length

$\mathrm{N}$ : number of turns of the field coil

The maximum magnetic flux density $\mathrm{B}_{\mathrm{m}}$ is measured as a function of the maximum magnetic field $\mathrm{H}_{\mathrm{m}}$. This is the first magnetization curve obtained with the $\mathrm{AC}$ supply. The area scanned by the hysteresis loop is also recorded. It is directly proportional to the total core losses (calculated as function of the maximum magnetic flux density level $\mathrm{P}\left(\mathrm{B}_{\mathrm{m}}\right)$ ). The measures are carried out with around $10 \%$ of incertitudes.

\subsection{Experimental results}

For a given $\mathrm{H}_{\mathrm{m}}$, we observe, as shown in figure 2, that $\mathrm{B}_{\mathrm{m}}$ is decreasing as the plastic strain increases. The amplitude of damage varies following two patterns. Below the knee of the magnetization curve, the different curves tend to diverge. Above the knee, the curves converge to the same magnetic saturation limit. $\mathrm{P}\left(\mathrm{B}_{\mathrm{m}}\right)$ curves calculated from the areas of the hysteresis loops and shown in figure 3 vary in a similar way to the first magnetization curves. Firstly we remark the important and out of standard-norm initial level of core losses in the specimens : $\mathrm{P}=6 \mathrm{~W} / \mathrm{kg}$ for $B_{m}=1.4 \mathrm{~T}$. This is due to the sinusoidal field strength $H(t)$, which induces a nonsinusoidal (trapezoidal) magnetic flux density $\mathrm{B}(\mathrm{t})$. This type of magnetic excitation increases losses. In undeformed specimens, we observe a parabolic increase of core losses with maximum magnetic flux density. The plastic strain causes at first a divergence of the curves (up to 0.9 Tesla), and then a convergence. 


\subsection{Establishment of the models}

This part of the work concerns models developed to find simple relations between the main magnetic properties and plastic strain. In this paper the least squares method is employed for all numerical calculations of parameters in our models. The indicated incertitudes come from these calculations.

Concerning the first magnetization characteristic, the Fröhlich classical model is used ${ }^{6}$ ( $\alpha$ and $\beta$ are characteristic constants of the material) :

$$
B_{m}=\frac{H_{m}}{\alpha+\beta \cdot H_{m}} \quad \text { or } \quad B_{m}=\frac{(1 / \beta) \cdot H_{m}}{\left[(\alpha / \beta)+H_{m}\right]}
$$

The Fröhlich equation yields:

$$
B_{m}=G \cdot\left[1-\frac{A}{\left(A+H_{m}^{n}\right)}\right]
$$

where :

$$
\mathrm{G}=(1 / \beta) \quad \mathrm{A}=(\alpha / \beta) \quad \mathrm{n} \approx 1
$$

The parameters $\mathrm{G}, \mathrm{A}$ and $\mathrm{n}$ are numerically determined from each experimental curve ; they take a particular value for each plastic strain level (illustrated in table 1).

The results of this model (4) are shown in figure 2. The evolution of the parameters $\mathrm{G}, \mathrm{A}$ and $\mathrm{n}$ as functions of plastic strain is shown in figure 4 . The following relations are used to model this evolution :

$$
\begin{aligned}
& \mathrm{G}=\mathrm{a}_{1}\left(!_{\mathrm{p}}+\mathrm{b}_{1}\right)^{\mathrm{n}_{1}} \\
& \mathrm{~A}=\mathrm{a}_{2}\left(\varepsilon_{\mathrm{p}}+\mathrm{b}_{2}\right)^{\mathrm{n}_{2}} \\
& \mathrm{n}=\mathrm{a}_{3}\left(\varepsilon_{\mathrm{p}}\right)^{\mathrm{n}_{3}}+\mathrm{n}^{\circ}
\end{aligned}
$$


The different constants $a_{i}, b_{i}$ and $n_{i}$ used in relations (5) (6) and (7) are numerically determined. They depend on the nature of the material. We find similar values for the exponents $\mathrm{n}_{1}, \mathrm{n}_{2}$ and $\mathrm{n}_{3}(\approx 0.3)$.

Concerning the evolution of core-losses, the Steinmetz classical law ${ }^{6}, P=ß\left(B_{m}\right)^{m}$, is used to model the experimental results (figure 3 ). $\beta$ and $m$ parameters are numerically determined and take a particular value for each plastic strain level (table $1)$.

$\beta$ and $\mathrm{m}$ become functions of plastic strain and their evolution versus plastic strain is modelled using the following relations:

$$
\begin{aligned}
& \beta=\beta^{\circ}-\left[\frac{\mathrm{a}}{\left(\mathrm{b}+\varepsilon_{\mathrm{p}}\right)^{\mathrm{n}_{4}}}\right] \\
& \mathrm{m}=\mathrm{m}^{\circ}+\left[\frac{\mathrm{c}}{\left(\mathrm{d}+\varepsilon_{\mathrm{p}}\right)^{\mathrm{n}_{5}}}\right]
\end{aligned}
$$

The constants in relations (8) and (9) are numerically determined (figure 5). The exponents are $\mathrm{n}_{4}=0.34( \pm 0.05)$ and $\mathrm{n}_{5}=0.86( \pm 0.12)$.

Once the plastic strains are accounted for, $B_{m}=f\left(H_{m}\right)$ and $P=f\left(B_{m}\right)$ become three dimensional functions : $B_{m}=f\left(H_{m}, \varepsilon_{p}\right)$ and $P=f\left(B_{m}, \varepsilon_{p}\right)$.

\subsection{Discussion}

\subsubsection{Limits of validity}

The different models used show a range of validity induced by the mathematical limits of the functions $\mathrm{B}_{\mathrm{m}}\left(\mathrm{H}_{\mathrm{m}}\right)$ and $\mathrm{P}\left(\mathrm{B}_{\mathrm{m}}\right)$. Regarding the first magnetization 
characteristics, we note first that it does not give any information about the Rayleigh zone ; it may also not be valid below $100 \mathrm{~A} / \mathrm{m}$. Moreover, this model indicates a saturation limit $\mathrm{G}$ which increases with the plastic deformation level : once the curves have crossed (after $7500 \mathrm{~A} / \mathrm{m}$ ), the model becomes invalid. On the other hand, the model used for core-loss prediction remains very imprecise with respect to the global evolution of losses. This model becomes invalid above $1.4 \mathrm{~T}$ where a crossing of $\mathrm{P}\left(\mathrm{B}_{\mathrm{m}}\right)$ curves is observed.

\subsubsection{Influence of plastic strain on magnetic properties}

From a micromagnetic point of view, the aspect of the first part of the magnetization

curves is explained by the Bloch wall behaviour in an alternating field ${ }^{1-6}$; the second part of the curves should be attributed to the rotation of elementary magnetic moments. We observe that plastic strain has a larger influence on the Bloch wall motion than on the rotation of the magnetic moments. The influence on the Bloch wall motion can be explained by an increase of the density of dislocations due to plastic strain. These dislocations act as potential barriers which hinder the Bloch wall motion ${ }^{5-7}$. The behaviour of the core loss curves is very close to that of the first magnetization curves for the same reasons : Bloch wall motion requires more energy when the material is deformed ; in contrast, rotation of the elementary magnetic moments is less affected.

\subsubsection{Influence of the small strains}

Small strains have a strong influence on the fluctuations of the $\mathrm{P}\left(\mathrm{B}_{\mathrm{m}}\right)$ and $\mathrm{B}_{\mathrm{m}}\left(\mathrm{H}_{\mathrm{m}}\right)$ curves. This is illustrated by a rapid change of the main coefficients $(\mathrm{A}, \mathrm{B}, \mathrm{n}, \mathrm{m})$ at the initial stages of deformation. To confirm this observation, further experiments were carried out under a quasi static supply to measure the variation of coercive field strength $\mathrm{H}_{\mathrm{c}}$ with plastic strain : this parameter should be very sensitive to 
microstructural changes ${ }^{5-6}$. As shown in figure 6 , we find two stages. Between $0 \%$ and $0.4 \%$ of plastic strain, there is a rapid linear increase of $\mathrm{H}_{\mathrm{c}}$. Above $0.4 \%$, the slope becomes much smaller but the variation remains linear. $0.4 \%$ of plastic strain corresponds to the beginning of the real plastic strain hardening since below that, the metallurgical state of the material is characterized by the Lüders strain state ${ }^{8}$. This first stage of deformation involves marked changes of the microstructural state ${ }^{9}$ such as strong increase of the number of high potential barriers ${ }^{5}$, rapid multiplication of the number of dislocations ${ }^{10}$, influence of Cottrell atmospheres on the behaviour of dislocations $^{11}$. The later strain hardening stage is characterized by slower changes of the microstructural situation and so of the magnetic properties.

\section{Application to a punched Non Oriented 3\% Silicon - Iron sheet}

\subsection{Manufacturing of rotating electrical machine sheets}

The manufacture of rotating electrical machine rotor and stator sheets is often carried out by progressive-die methods requiring the use of high productivity presses. An example of successive stages of stamping is shown in figure 7 . This process involves a strong shearing at the cutting-edge and irreversible plastic strain is present after punching. Since as shown earlier in section 2, a direct relationship exists between the plastic strain level and the magnetic properties. The cutting operation should also have a significant effect on the magnetic properties of rotating electrical machine sheets. SCHMIDT ${ }^{12}$ showed that relations exist between the change of the first magnetization curve, the increase of core-losses and the cut length for a N.O. 1\% Silicon - Iron sheet. SZYMURA and ZAWADA 13 observed a similar phenomenon for grain-oriented 3\% Silicon - Iron.

\subsection{Measurement of strain after cutting}


The aim of the present work is to apply models which have been developed, to a particular example of cutting and a punching test which is close to industrial manufacturing processes has been chosen. In a first approach, two sheets were tested using the magnetic circuit which has been described earlier. Each sheet was punched by three holes. One sheet was annealed $\left(720^{\circ} \mathrm{C}, 2 \mathrm{H}, \mathrm{P}\left(\mathrm{O}_{2}\right)=2.10^{-4}\right.$ Torr $)$ to eliminate plastic strains. The results of this test are shown in figure 8 where a significant influence of plastic strain can be seen on the knee of the magnetization curve (decrease of the maximum permeability). This result confirms the effect of plastic strain close to the cutting edge.

Local plastic deformation after cutting cannot be measured directly, so a microhardness test ${ }^{14-15}$ has been used since MAILLARD 15 showed that it was possible to find a relationship between the plastic strain in a metal sheet and hardness. In the present work, the hardness was measured in specimens plastically deformed to different amounts. Hardness was measured on the vertical axis section of the "useful deformed part" of the specimens. A Vickers microhardness (HV) test was used because the indentation is small enough $(\approx 30 \mu \mathrm{m}$ diagonally) to allow the measurement of hardness changes over small distances. A HV $=\mathrm{f}\left(\varepsilon_{\mathrm{p}}\right)$ function is obtained, which is used to deduce plastic strain level close to the cutting edge of a punched metal sheet.

\subsection{Relationship between plastic strain after cutting and after tensile test}

Vickers microhardness measurements have been carried out on numerous plastically deformed specimens and the $\mathrm{HV}=\mathrm{f}\left(\varepsilon_{\mathrm{p}}\right)$ relation is also valid for any uniaxial tensile test. But the punching test induces a complex deformation state, with strong shearing of the material. This situation meant that a multiaxial criterion had to be used in the three dimensional space of plastic strains. The isotropy of the mechanical properties of the silicon-iron material has first been verified after tensile testing along the rolling, tranverse, and $45^{\circ}$ angle directions. As a consequence, we chose the Levy- 
Mises criterion 16 which expresses the equivalent plastic deformation $\varepsilon_{\mathrm{eq}} \mathrm{p}$ as a function of the principal plastic deformations $\left(\varepsilon_{\mathrm{I}}^{\mathrm{p}}, \varepsilon_{\text {II }}^{\mathrm{p}}, \varepsilon_{I I I} \mathrm{p}\right)$ along the three principal directions $\left(\mathrm{x}_{\mathrm{I}}\right.$ : traction direction, $\mathrm{x}_{\mathrm{II}}$ : width direction, $\mathrm{x}_{\mathrm{III}}$ : thickness direction) :

$$
\mathrm{d} \varepsilon_{e q}^{\mathrm{p}}=\sqrt{\frac{2}{9}\left(\left(\mathrm{~d} \varepsilon_{I}^{\mathrm{p}}-\mathrm{d} \varepsilon_{I I}^{\mathrm{p}}\right)^{2}+\left(\mathrm{d} \varepsilon_{I I}{ }^{\mathrm{p}}-\mathrm{d} \varepsilon_{I I I}^{\mathrm{p}}\right)^{2}+\left(\mathrm{d} \varepsilon_{I}^{\mathrm{p}}-\mathrm{d} \varepsilon_{I I I}^{\mathrm{p}}\right)^{2}\right)}
$$

The plastic strain takes place at constant volume and the deformation is homogeneous so that the the following relation is experimentally verified :

$$
\mathrm{d} \varepsilon_{\text {II }}{ }^{\mathrm{p}} \approx \mathrm{d} \varepsilon_{\text {III }} \mathrm{p} \approx-(1 / 2) \mathrm{d} \varepsilon_{\mathrm{I}}^{\mathrm{p}}
$$

The following relations are immediately obtained :

$$
\mathrm{d} \varepsilon_{\mathrm{eq}}^{\mathrm{p}}=\mathrm{d} \varepsilon_{\mathrm{I}}^{\mathrm{p}} \quad \Rightarrow \quad \varepsilon_{\mathrm{eq}}^{\mathrm{p}}=\varepsilon_{\mathrm{I}}^{\mathrm{p}}=\varepsilon_{\mathrm{p}}
$$

Uniaxial plastic strain can also be identified to equivalent plastic strain for the particular sheet used : $\mathrm{HV}=\mathrm{f}\left(\varepsilon_{\mathrm{p}}\right)$ is equivalent to $\mathrm{HV}=\mathrm{f}\left(\varepsilon_{\mathrm{eq}}{ }^{\mathrm{p}}\right)$. This relation can then be employed immediately after a microhardness test on the cutting edge of a punched N.O. 3\% Silicon - Iron sheet to deduce the local equivalent plastic strain level.

\subsection{Results : derivation of a $\mathrm{HV}=\mathrm{f}\left(\varepsilon_{\mathrm{eq}}{ }^{\mathrm{p}}\right)$ law}

The results are shown in figure 9. The microhardness value increases rapidly in the initial stages of plastic deformation. The rate of increase then slows down. This curve can be compared with the stress-strain curve of this material.

The fitting law chosen is that used to model the mechanical behaviour of colddrawable materials $15-16$ : 


$$
\mathrm{HV}=\mathrm{HV}^{\circ}+\delta \cdot\left(\varepsilon_{\mathrm{eq}}^{\mathrm{p}}\right)^{\alpha}
$$

$\delta$ and $\alpha$ oefficients are numerically calculated. The strain-hardening coefficient is : $\alpha=0.41( \pm 0.03)$. The initial hardness is $\mathrm{HV}^{\circ}=196( \pm 3) . \delta=19.5( \pm 1.2)$

\subsection{Application to a punching test}

\subsubsection{Experiment}

A punching test machine has been made which is coupled with a tension / compression machine. The punching speed is $1 \mathrm{~mm} / \mathrm{min}$. The diameter of the holes is $5 \mathrm{~mm}$. Experiments were carried out under normal conditions : $20{ }^{\circ} \mathrm{C}$, atmospheric pressure.

\subsubsection{Microhardness measurements}

The punched sheet was cut along a diameter of a hole and polished on the transverse section. Numerous microhardness tests were made close to the cutting edge on the polished section. The first results consisted of iso-hardness maps (as shown in figure 10). These three-dimensional data $(\mathrm{HV}, \mathrm{x}, \mathrm{y})$ were transformed to twodimensional ones giving hardness value as a function of the distance from the cutting edge (figure 11). The variation of microhardness can be modelled as follows :

$$
\mathrm{HV}=\mathrm{HV}^{\circ}+\frac{\mathrm{p}}{(\mathrm{x}+\mathrm{q})^{\mathrm{r}}}
$$

with $\mathrm{x}$ the distance from the cutting edge given in $\mathrm{mm}$. 
The constants $\mathrm{p}, \mathrm{q}$ and $\mathrm{r}$ are numerically calculated. The exponent $\mathrm{r}$ is significantly large $(r=4.9( \pm 2.0))$, the decrease of $\mathrm{HV}=\mathrm{f}(\mathrm{x})$ is consequently fast. Incertitudes in this model are important because the dispersion of results is important. $(p=21( \pm 5)$, $\mathrm{q}=0.64( \pm 0.30) \mathrm{mm})$.

\subsubsection{Development of complete models}

From $\mathrm{HV}=\mathrm{f}(\mathrm{x})$ and $\mathrm{HV}=\mathrm{f}\left(\varepsilon_{\mathrm{eq}}^{\mathrm{p}}\right)$ a relation $\varepsilon_{\mathrm{eq}} \mathrm{p}=\mathrm{f}(\mathrm{x})$ can easily be deduced, giving equivalent plastic deformation level versus distance from the cutting edge :

$$
\varepsilon_{\mathrm{eq}}^{\mathrm{p}}=\frac{\mathrm{K}}{(\mathrm{x}+\mathrm{q})^{\mathrm{u}}}
$$

This curve plotted in figure 11 gives information concerning the zone affected by the punching in spite of the strong incertainties $(K=2.5( \pm 1.3))$. Plastic strain is very high at the cutting edge, decreases rapidly (the exponent $\mathrm{u}$ is very high : $\mathrm{u}=12( \pm$ 4)), and is lower than $0.5 \%$ after $x=0.5 \mathrm{~mm}$. However, the effect of the small plastic strains on the magnetic properties is not negligible and in practice, the influence zone of the punching extends up to $1 \mathrm{~mm}$ from the cutting edge.

On the other hand, knowing the relationship between the change of magnetic properties and plastic deformation (after a tensile test), the two kinds of profiles of magnetic properties can be deduced : [Magn. Prop.] $=\mathrm{f}(\mathrm{x}) . \mathrm{B}_{\mathrm{m}}\left(\mathrm{H}_{\mathrm{m}}\right)$ and $\mathrm{P}\left(\mathrm{B}_{\mathrm{m}}\right)$ curves become $\mathrm{B}_{\mathrm{m}}\left(\mathrm{H}_{\mathrm{m}}, \mathrm{x}\right)$ and $\mathrm{P}\left(\mathrm{B}_{\mathrm{m}}, \mathrm{x}\right)$ three-dimensional functions, which have been plotted in figure 12.

\subsubsection{Future developments}

The next stage would consist in modelling such a punched sheet via a numerical finite element method with a sufficiently refined mesh. Then, the $B_{m}\left(H_{m}, x\right)$ and 
$\mathrm{P}\left(\mathrm{B}_{\mathrm{m}}, \mathrm{x}\right)$ characteristics of different elements would be affected as function of their mean distance from the cutting edge. This may result in an improvement of the modelling procedures of rotating electrical machines. Of course, many improvements may be possible concerning the global precision of results and models, so that incertitudes of parameters could decrease.

\section{Conclusion}

The present work consisted first of an attempt to develop new functions allowing a "plastic strain level" parameter to determine $B_{m}\left(H_{m}\right)$ and $P\left(B_{m}\right)$ curves of a Non Oriented 3\% Silicon - Iron sheet. The equivalent plastic strain profile $\varepsilon_{e q} p=f(x)$ near the cutting edge of the same punched material were then measured. This last relation has been obtained using a Vickers microhardness test. A mathematical function giving magnetic properties profiles versus distance from the cutting edge followed, which could be introduced into numerical models (mainly finite element modelling) of rotating electrical machines.

\section{Acknowledgements}

The authors wish to thank professors M.CLAVEL and M.KANT for their assistance and useful discussions. 


\section{$\underline{\text { References }}$}

1. J.V.S.MORGAN, K.J.OVERSHOTT: IEEE Trans. Mag. , Sept. 1978, 14, (5), 770-772.

2. J.DEGAUQUE: Mem.Etudes Scient.Rev.Metal, Jan. 1985, 5-23.

3. F.DUMAS, E.HUG, M.CLAVEL, J.L.ILLE: Journal de Physique IV - colloque C3, 1992, 2, 47-51.

4. L.J.DIJKSTRA, C.WERT: Phys.Rev., 1950, 29, (6), 979-985.

5. R.VERGNE, J.C.COTILLARD, J.L.PORTESEIL: Rev. Phys. Appl., 1981, (16), 449-476.

6. D.JILES: 'Introduction to magnetism and magnetic materials', (ed. Chapmann and Hall), 1991.

7. E.HUG. Thesis, ed UTC, 1993.

8. H.NEUHAUSER, A.HAMPEL: Scripta Metallurgica, 1993, 29, 1151-1157.

9. M.J.WHELAN: Mem.Scient.Rev.Metal., 1959, (2), 153-161.

10. J.L.STRUDEL: in école d'été d'Yravals, 'Dislocations et déformation plastique', Sept.1979, 307-326.

11. A.H.COTTRELL, B.A.BILBY: Proc. Phys.Soc., 1949, A62, 49-62. 
12. K.H.SCHMIDT: JMMM, 1976, (2), 136-150.

13. S.SZYMURA, A.ZAWADA: J. Mater. Sci., 1981, 16, 3194-3198.

14. J.LEMAITRE, J.DUFAiLly, R.BILLARDON. C.R. Acad. Sc. Paris, 1987, t. 304, Série II, (12), 601-604.

15. M.MAILLARD. Thesis, ed CETIM, 1991.

16. Y.ADDA, J.M.DUPOUY, J.PHILIBERT, Y.QUERE: 'Eléments de métallurgie physique - Déformation plastique' , (ed CEA), 2ème ed. 1987, 5, 1717-1764.

17. Collectiv publication :'Blanking and piercing of magnetically soft materials (electrical sheet)', in Metals Handbook, 8ème ed. 1969, 4, 60-68. 